\title{
TECHOLOGY ENHANCED PROFESSIONAL LEARNING Process, Challenges and Requirements
}

\author{
Mohamed Amine Chatti, Ralf Klamma, Matthias Jarke \\ RWTH Aachen University,Informatik V, Ahornstr. 55, 52056 Aachen, Germany \\ chatti@cs.rwth-aachen.de,klamma@cs.rwth-aachen.de,jarke@cs.rwth-aachen.de \\ Vana Kamtsiou, Dimitra Pappa \\ National Center of Scientific Research "Demokritos", 15310 - Agia Paraskevi Athens P.O. 60228 \\ vana@dat.demokritos.gr,dimitra@dat.demokritos.gr \\ Milos Kravcik \\ Fraunhofer-Institut für Angewandte Informationstechnik FIT, 53754 Sankt Augustin, Germany \\ Milos.Kravcik@fit.fraunhofer.de \\ Ambjörn Naeve \\ Royal Institute of Technology, 10044 Stockholm, Sweden \\ amb@nada.kth.se
}

Keywords: Technology Enhanced Professional Learning, Learning Process, Learning and Knowledge Management.

Abstract: $\quad$ Since we cannot transfer knowledge from one person to another person, learning, also known as knowledge creation, is the social process of acquiring and applying knowledge. Our claim is that the oscillating process of knowledge acquisition and application for workplace learning can be best described by the SECI model introduced by Nonaka in 1994. In this paper, we analysis the learning process in terms of the SECI model, identify the challenges for technology enhanced professional learning and define the requirements for future applications such as personalized adaptive learning. We report the results of a roadmap survey done in the framework of PROLEARN to disclose the desired state of the art in technology enhanced professional learning in the year 2015 and show ways how to proceed on the way to the desired state.

\section{INTRODUCTION}

The knowledge age is demanding higher skilled jobs, based on critical thinking, creativity, collaboration, and interpretation abilities. Additionally, the percentage of "knowledge workers" is rapidly increasing and $50 \%$ of all employee skills become outdated in three to five years (Moe, Blodgett, 2000). Therefore, using only traditional methods of training cannot cover today's educational needs. Many authors have recognized the new demands on one hand and new potential on the other. In the following we mention some of them. Roger C. Schank revises the concept of intelligence. In the future intelligence will mean ability to reach the boundaries of the knowledge base (Schank, 2002). Peter Drucker sees new horizons. He cites that education requires focusing on the strengths and talents of learners (Drucker, 1989). Alfred Bork considers current and new paradigms concerning technology and learning. $\mathrm{He}$ argues that we need much better learning for all and this learning has to be affordable for the individual and the world (Bork, 2001). Wayne Hodgins presents the grand vision of meLearning that will provide personalized learning experiences to every person on the planet every day and when the learner is ready the "teacher" will appear (Hodgins, 2005). In the past few years, attention has been shifting towards the importance of knowledge management in corporate and academic learning environments (Lytras et al., 2005). Researchers and companies are starting to recognize relationships between knowledge management and technology enhanced learning research fields and to explore the potential 
of their combination into one integrated program, process, philosophy and approach (Stacey, 2000), (Hall, 2001), (Hackett, 2001), (Efimova, Swaak, 2003), (Naeve et al., 2005). Not surprisingly, there are several commonalities between learning management (LM) and knowledge management (KM) (Grace, Butler, 2005). Both share a similar purpose: how to enhance human knowledge and its application. In this paper we go a step further and we argue that learning management solutions and KM solutions have to fuse, and that we should speak about merging and fusion of the two fields rather than intersection or complementary relationship between them. In this work, we address the following important questions: Why are LM and KM two sides of the same coin? What does the learning process look like? What are the requirements to make the learning process work better? What is the future potential of learning at the workplace?

The rest of the paper is structured as follows: Section 2 explores the integration of LM and KM. Section 3 defines learning concepts and points to the relationship between learning and knowledge. Section 4 focuses on the elements of the learning process. Section 5 explores the challenges, and requirements of learning at workplace. Finally, Section 6 gives a summary of the paper and outlines perspectives for the future.

\section{LEARNING \& KNOWLEDGE MANAGEMENT}

Relationships between KM and LM on the one hand and between KM and computer science on the other hand has been discussed by many researchers (Jarke, Klamma, 2002). In this section, we argue that learning and KM are two sides of the same coin and terms from the two fields can be used interchangeably. Knowledge is information that changes something or somebody, either by becoming grounds for actions, or by making an individual (or an institution) capable of different or more effective action (Drucker, 1989). Naeve defines knowledge as "efficient fantasies", with a context, a purpose and a target group, with respect to all of which their efficiency should be evaluated (Naeve, 2005). Knowledge can be of different types, such as know what, know how, know why, and know who. Know what refers to knowledge about facts, concepts, categories, descriptors and information. Know how refers to knowledge of how something occurs or is performed. Know why refers to knowledge why something occurs (Stacey, 2000). Know who refers to knowledge about persons who are in possession of important and valuable knowledge. The same might be said of learning. Learning comprises learn what, learn how, learn why, and learn who. These learning types will be discussed in more details in the next section.
$\mathrm{KM}$ is not easy to precisely define. In the Learning Circuits glossary, $\mathrm{KM}$ is defined as the process of capturing, organizing, and storing information and experiences of workers and groups and making it available to others (Learning Circuits Glossary, 2005). In practice, KM often encompasses identifying and mapping intellectual assets within the organization, generating new knowledge for competitive advantage within the organization, making vast amounts of corporate information accessible, sharing of best practices, and technology that enables all of the above (Barclay, Murray, 1997). In terms of output, KM is about getting the right knowledge to the right people, in the right form and in a timely fashion, so they can do their best work (Hall, 2001). To summarize, we can say that capturing and managing knowledge, placing people at the center, creating a culture where knowledge sharing is the norm, and providing technological capabilities and possibilities are the main aspects of KM. These are also the primary goals of LM which deals with connecting people to quality learning resources as well as people to people (learner to learner and learner to facilitator).

Technology enhanced learning platforms and formal training programs are becoming essential parts of organizational KM. On the contrary, KM methods and techniques are being adopted in learning environments. These methods include fostering of communities of practice (Wenger, 1998) and knowledge sharing within learning environments as well as using repositories to store learning components. Tools such as live chat rooms, instant messengers, video conferencing, and knowledge repositories represent some of the techniques from the KM field that are being applied in the learning process. Furthermore, some terminologies and concepts that are currently being applied in the learning context, such as learning management system (LMS), learning object, learning asset, and learning base, are in fact borrowed from the KM field (Grace, Butler, 2005). In a KM context, we speak about knowledge management system (KMS) as "a system that provides support for many information functions, including: acquiring and indexing, capturing and archiving; finding and accessing; creating and annotating; combining, collating and modifying; and tracking" (Edmonds, Pusch, 2002), about knowledge object as "any document, schematic, drawing, tool, software, job aid, or guide that helps people do their work" (Allee, 2000), about knowledge asset as "Intellectual content possessed by an organization ", and about knowledge base as "a specialized database that stores knowledge assets" (Learning Circuits Glossary, 2005).

Let us start from the definition that KM is the collection of the following processes: create, transform, organize, store, disseminate, share, deliver and use knowledge. Take a learning resource. Decompose it into granular and reusable 
learning assets. Support communities where social interactions can take place. Use technology that on the one hand helps delivering the right learning content to the right person and on the other hand allows posting new useful learning content. What will be the result? Something that is quite similar to KM.

\section{TECHNOLOGY ENHANCED LEARNING}

Learning is leaving the training classroom and becoming an indispensable ingredient of living and working in our society (Watkins, 2005). It can be viewed both as knowledge or skill and as an applied process. Wayne Hodgins defines learning as a knowledge and social skill that has to be learned and continuously improved. It is one of the new basic skills of the future (Hodgins, 2000). This crucial skill comprises learn what, learn why, learn how, learn where, and learn who. Learn what refers to the learning stuff needed and the high-quality learning object that has to be acquired. Learn why refers to the definition of effective learning goals. The main aim of learning is to improve human performance and increase the ability of any individual, project team, or organization. Acquiring new knowledge is itself not the purpose of learning. We learn in order to better perform, integrate the gained knowledge in our daily work to solve problems and achieve the desired end result, create innovative knowledge and better ideas that lead to more success, and share our own knowledge with others. In that sense, a learner becomes a knowledge worker. That is, someone who doesn't just consume knowledge but who is able to create it. Learn how refers to how learning occurs. It includes how to acquire new knowledge (e.g. through reading, professional training, discussions with peers, formal studies or research), how to apply knowledge effectively, how to generate, design, plan, structure, capture, store, evaluate, manage, use, disseminate, deliver learning assets, how to build a learning environment that encourages knowledge sharing, and how to use technology such as collaborative tools. Since learning nowadays is conceptualized as a social system within communities of practice (Wenger, 1998), (Spaniol et al., 2006), the best way to learn is with others, in groups. Learn how also involves the knowledge how other people learn which is critical to ensure the creation of engaging learning experiences (Stacey, 2003). Learn where refers to how to locate appropriate information and where to look for quality learning objects. As Albert Einstein once said "don't memorize anything you can look up", it is worthwhile to learn where to find relevant knowledge or communities working on it, rather than memorizing the knowledge itself. Finally, learn who refers to technological and human learning facilitators that can provide learning support. It also refers to experts who are in possession of valuable knowledge.

Learning can also be seen as a process (Naeve, et al., 2005). In the Learning Circuits glossary, Learning is defined as a cognitive and/or physical process in which a person assimilates information and temporarily or permanently acquires or improves skills, knowledge, behaviours, and/or attitudes (Learning Circuits Glossary, 2005). According to Hodgins, learning is not a mechanical, static, linear process, nor one that can be understood by examining any of its components outside of its systemic context. It is a very human, dynamic, and complex flow that resembles an organic structure more than a mechanical one (Hodgins, 2000). Learning is an action-oriented as well as a social process. It is the continuous process of gaining existing personalized knowledge leading to the creation of new knowledge. It is thus the cyclic transition of knowledge acquisition and knowledge application. The learning process and its components will be described in details in the next section. In this section, we do not distinguish between professional learning and academic learning. We rather focus on learning itself as a skill and process aiming at enhancing the personal and professional performance and a means to improvement and effectiveness.

\section{LEARNING PROCESS}

The learning process concepts discussed in this section are abstracted from Nonaka and Takeuchi's SECI cycle, given in their book "The knowledge creating company" (Nonaka, Takeuchi, 1995). According to these authors, there are two different kinds of human knowledge: tacit knowledge and explicit knowledge. Tacit knowledge - a term introduced by Michael Polanyi in 1967 - is the personal and hidden knowledge which resides within the mind. Examples of tacit knowledge are know how, expertise, understandings, experiences and skills resulting from previous activities. Tacit knowledge is personal and hard to formalize, codify or communicate. Unlike tacit knowledge, explicit knowledge is codified, systematic knowledge that can be transmitted in formal language. It can easily be captured, accessed and shared. Similar to the knowledge creation process, the learning process is knowledge in action, a cyclic conversion of tacit knowledge and explicit knowledge. This spiraling, highly dynamic and complex process is modeled in the figure below. It consists of four modes: socialization, externalization, combination, and internalization. These modes occur when tacit and explicit knowledge interacts with each other. In the following four sections, we examine each of these modes. 


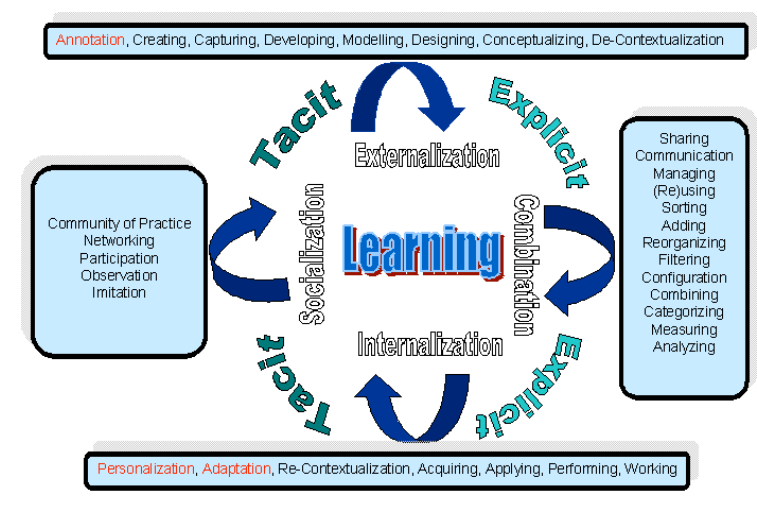

Figure 1: Learning Process

\subsection{Socialization}

Socialization is the first mode in the learning process and the primary source of learning. As Polanyi (1967, p. 4) mentioned "We know more than we can tell". There is a huge mass of highquality tacit knowledge embedded in people, which is not easily expressible. This knowledge can, however, be made available to others through socialization. In this mode, learning occurs implicitly, within a social context through observation, imitation, participation, interaction and practice, rather than through written or verbal communication (e.g. on the job training). The process of acquiring tacit knowledge can be supported by joint activities, personal connections, social networking, and community of practice (CoP) building. CoP "are focused on a domain of knowledge and over time accumulate expertise in this domain. They develop their shared practice by interacting around problems, solutions, and insights, and building a common store of knowledge" (Wenger, 1998). Therefore, a learning system should include an effective collaborative learning environment that can encourage tacit knowledge sharing and facilitate socialization.

\subsection{Externalization}

Through externalization, tacit knowledge is made explicit, i.e., expressed in language or symbols, in a form which can be accessed, understood, shared, adapted, and reused. The conversion of tacit into explicit knowledge involves techniques that help to express one's ideas or images as words, concepts, figurative language (such as metaphors, analogies or narratives) and visuals (Nonaka, Konno, 1998). Externalization is a complex process aiming at creating high-quality and valuable learning objects. In the externalization process, software engineering concepts and principles should be applied. The first step in this process is knowledge decontextualization. That is, extract knowledge from its context such that it is not bound to the situation from which it stems, thus enabling the reusability of this knowledge in different learning situations. The next step is planning. That is, define a set of goals and requirements that need to be achieved. Good planning will leverage the created learning object (i.e. knowledge component) to its best use. Parts of the planning process are on the one hand to determine the target user's needs, preferences, interests, skills, learning goals, background and on the other hand to fix the knowledge level that he/she will have acquired at the end. Modeling and modularity are the cornerstones of the externalization process. It is crucial to disaggregate a learning resource into tiny learning objects and identify how these objects relate to each other. Those modular learning objects can then be reused by different user communities for diverse purposes. Once the objectives of the new learning resource are defined and modular learning objects are identified, it is possible to move to the development step using all software and hardware means that are able to reduce the time to develop valuable learning content such as simulations and experiments. The result of the application of software engineering concepts in the knowledge capturing process will be granular, organized and reusable learning objects.

Successful knowledge capturing also requires the use of metadata for describing learning objects as well as adopted, common, open and accredited standards (Hodgins, 2000). According to Hodgins, metadata is the full and rich set of information needed in order to find, filter, select, and combine the information. Metadata becomes increasingly important and is required to annotate learning resources in order to support indexing, storage, search, and retrieval of appropriate learning resources or learning paths relevant for a specific learner or a group of similar learners (Chatti et al., 2005). It is also crucial to use standards for metadata and learning objects to provide fixed data structures and communication protocols for learning objects and cross-system workflows (Ellis, 2005) and assure accessibility, interoperability, adaptability, reusability, durability, and affordability of learning (Hodgins, 2000). Furthermore, since knowledge must be current in order to be of value, attention should be paid to the development of up-to-date and dynamic learning resources. A possible way to achieve this is, instead of inserting an existing learning object into a learning resource, just to point directly to the community which is currently working on the development of this object. To achieve best results from the externalization process, a learning system should include a standard-based, collaborative and effective knowledge capture system (can also be called a knowledge representation system or an authoring system) that supports learning communities in designing, creating, reviewing, modifying, and posting up-to-date and valuable learning objects in a short time. This system should particularly include an intelligent component for automatic learning object annotation, which is 
based on powerful data mining algorithms and advanced pattern recognition techniques.

\subsection{Combination}

As discussed in the previous section, the output of the externalization process is granular, annotated, classified, context free, standard-based, and up-todate learning objects (i.e. explicit knowledge). These quality learning objects can now be shared, disseminated, stored, reused, analyzed, recategorized, re-contextualized, reconfigured, reorganized, combined, and delivered. The manipulation of existing learning objects leads to new, possibly more complex learning objects. This process is referred to as combination. The combination process is supported by learning repositories to store and manage learning objects and their associated metadata, as well as learning paths and activities. In case these repositories are based on standards for interoperability and reusability, they can be accessed and managed so that they are available as a virtual single pool of learning objects and metadata (Hodgins, 2000). In a learning repository, new modular learning objects can be added and existing ones can be analyzed, compared, sorted, restructured and associated. This results in new learning object configurations and combinations or new learning paths that can be applied to address different learner needs and solve new problems.

In addition to learning repositories, the combination process is most efficiently supported in collaborative environments utilizing information technology (Nonaka, Konno, 1998). Stacey mentioned that active and alive learning environments are more like learning communities than learning repositories. They focus on bringing people to people not just people to content (Stacey, 2003). According to this, learning has to occur within a social context which supports listening, viewing, reading, writing, speaking, commenting, suggesting, asking, discussing, disseminating, and sharing of learning objects and best practices among community members (i.e. academic and professional novice/mature learners, customers in an organizational context, peers, learning facilitators, coordinators, mentors, experts). To help building the required personal connections in an online social network, the use of synchronous and asynchronous communication tools is crucial (e.g. e-mail, instant messaging, video conferencing, Voice-Over-IP, group scheduling, announcements, news, events, calendar, weblogs, wikis, webfeeds). In addition to learning repositories and learning communities, powerful access and search capabilities across content, metadata and people are required. A learner should be able to query the learning system to quickly locate appropriate learning resources, as well as persons who share his/her interests or experts who can help achieving better results.

\subsection{Internalization}

Internalization is the conversion of explicit knowledge into new tacit knowledge (Nonaka, Konno, 1998). In the learning process, internalization refers to the embodying of knowledge through reflection and application of the gained explicit knowledge in a given context. It is closely related to learning by doing, performing, and working. In the internalization process personalization is the key. Personalization is the ability to get just the right stuff to just the right person at just the right time and place in just the right way and with just the right context on just the right device and through just the right medium (Hodgins, 2000). The learning system should include an intelligent personalization/adaptation engine, able to deliver quality learning resources that are tailored to the learner's needs, preferences, interests, skills, learning goals, cultural background. Learner modeling is the cornerstone of the personalization process. Therefore, a learning system has to have access to the learner information and handle learner models to determine which content is the most appropriate and provide the learner with learning resources or complete learning paths tailored to his/her needs (Chatti et al. 2005). A learner model reflects information that is specific to each individual learner such as current knowledge level, performance, progress, learning objectives, personal interests and preferences as well as the topics from the supported learning domain that the learner has already covered. To describe a learner model, standards to share information about learners across multiple learning systems and metadata to search and retrieve similar learner models are required. A possible way to achieve personalization is to associate each learning object and each learner model with metadata, relate each learning object with one or more suitable learner models, choose the potentially right learning objects and assemble them to a learning path by applying similarity rules to the learning objects and learner models metadata, give recommendations based on old experiences and previously solved problems, place the learner at the center by giving $\mathrm{him} / \mathrm{her}$ the chance to negotiate the learning experience and to evaluate this experience afterwards. To enable this, we would need a database for learning objects, learner models and their respective metadata, as well as an experience database that will constantly be updated and rectified.

Often forgotten, we want to address two other issues: (a) the prerequisites for any knowledge transformation and (b) a phase model for organizational knowledge creation. This phase model of learning (sharing tacit knowledge, 
creating concepts, justifying concepts, building an archetype, cross-leveling of knowledge) makes clear that learning is an action-oriented process. The aim of organizational knowledge creation is to build something (the archetype). With the crossleveling of knowledge the process starts again. As important as the process model are the prerequisites of learning which are intention, autonomy, fluctuation and creative chaos, redundancy and requisite variety. All these ideas might amount to a nightmare for western style organizations. However, Nonaka and Takeuchi are arguing that these prerequisites are inevitable. Furthermore, the concept of 'ba' (Nonaka, Konno, 1998) and the concept of CoP (Wenger, 1998) are quite similar.

\section{TEPL: CHALLENGES \& REQUIREMENTS}

This section reports the results of a survey done in the framework of PROLEARN, the EU Network of Excellence dealing with technology enhanced professional learning (Wolpers, Grohmann, 2005). This survey is part of an effort to construct a roadmap that aligns business drivers with enabling technologies to provide a logical framework for coordinating $R \& D$ to meet the grand challenges of European Technology Enhanced Professional Learning (TEPL). Some of the key questions raised in the context of this work are: What are the envisaged forms of TEPL in 2015 (future states of TEPL) and what factors are they going to be influenced by in the future? It is commonly acknowledged that the new, knowledge-based global economy presents more complex challenges to workers, requiring new paradigms of learning, computer literacy, critical thinking, information analysis and synthesizing skills. A knowledge society cannot exist without highly educated citizens and a well-trained workforce. Globalization, competition and labor shortages cause employees to work longer, harder and travel more. Professional lives are changing continuously and require specific knowledge, skills and competences. New work forms are emerging and become rapidly adopted. Production cycles, and life-spans of products and services continue to shorten, causing information and training to quickly become obsolete. At the same time, workers require more independence and responsibilities in their jobs and dislike close supervision. Based on the above, and according to the early findings of the PROLEARN survey, in the future, TEPL should serve as a means to support knowledge workers, promoting motivation, performance, collaboration, innovation, and commitment to lifelong learning. This vision of learning entails: (a) TEPL becoming an effective tool for enterprises to support and enhance work performance and promote innovation, creativity and entrepreneurship among their employees; (b) learning becoming a catalyst in increasing employability (flexibility and survivability of employees); (c) democratizing the provision and use of knowledge in order to provide equal opportunities for high quality learning for all; (d) enabling and empowering everyone to learn anything at anytime at anyplace; and (e) commoditizing the professional TEPL market, in order to achieve transparency.

In the context of this vision of the future, a knowledge worker reflects critically on his/her professional activities and contributes back. The success of learning in a professional setting is influenced by a number of external factors, (e.g. technological, social, cultural, political and economical). In the course of its survey of influential factors, PROLEARN has developed a classification scheme that categorizes factors according to their impact and predictability, taking also into consideration the level of agreement of the respondents, as depicted in Figure 2. Dismissing factors that according to the majority of the survey participant appear to have no impact on TEPL, PROLEARN focuses on 6 classes of factors, ranging from factors with almost unanimously agreed high impact on TEPL which are mostly predictable (Class 1, important trends) to currently unpredictable trends that the majority viewed as being of low impact on TEPL but with strong opposition (Class VI). The results of phase 1 of the survey are summarized in the following sections.



Figure 2: Classification of influential factors

\section{Class I}

Class I includes factors with almost unanimously agreed high impact on TEPL which are predictable. Economical Factors include (a) many new partnerships (e.g. between vendors, academics, government agencies and industry consortia) will emerge; (b) in workplace learning, learning technology applications will be integrated into wider enterprise applications suites, creating seamless learning and working environments; (c) $\mathrm{KM}$ and TEPL applications will be increasingly integrated.

Technological Factors include (a) tomorrow's technologies will compress the production cycle of TEPL content; (b) massive issues (e.g. of spam, viruses, identity theft, intellectual property, and legality) will not cause the Internet to collapse; (c) 
the ability of ubiquitous Internet access linked with high bandwidth will have created a potential for two-way interactive collaboration; (d) the use of metadata will facilitate the search for, as well as the management and the aggregation of content objects; (e) online communities will be providing inspiration for new ways of learning.

Socio-cultural Factors include (a) education and training will be more flexible and tailored according to learner needs; (b) there will be more networks between institutions, making it possible for a learner to compile his/her education by choosing learning modules from different institutions.

\section{Class II}

Class II includes factors with almost unanimously agreed high impact on TEPL not predictable.

Technological Factors include (a) the development of TEPL will be intrinsically linked to the evolution of new telecommunications technologies that offer both ubiquitous access and relatively cheap high bandwidth connectivity (b) the development of common standards will have progressed satisfactorily; (c) both complex delivery systems and software applications will be made to support various learners with different learning styles; (d) learning modules will be developed according to standards and therefore will be easily customized for learning anytime, anywhere.

Political Factors include (a) education policies adjust to new learning methods and technologies; (b) a poor economic climate leads to cutbacks and reduced funding for e-training by governments.

Socio-cultural Factors include (a) social climate is driven by forces that encourage sharing, open exchange and free collaboration, where people can trust and learn from each other; (b) the social climate is driven by instincts of control, suspicion and distrust; (c) with global communications widening horizons people's identities are less shaped by their nationalism and more by their interest and motives.

\section{Class III}

Class III refers to mostly predictable factors that the majority viewed as being of high impact on TEPL but with strong opposition.

Technological Factors include people will refrain from using technology in their learning because technology will become too complicated.

\section{Class IV}

Class IV refers to unpredictable factors that the majority viewed as being of high impact on TEPL but with strong opposition. No survey statements were classified under this category.

\section{Class V}

Class $\mathrm{V}$ includes mostly predictable factors that the majority viewed as being of low impact on TEPL but with strong opposition.

Economical Factors include (a) globalization will lead to a future where the content of training will be internationalized; (b) tough economic climate is a driver for cutting costs in training within companies; (c) TEPL suppliers will use low cost labor countries, e.g., India, Asia, new EU member states, for an increasing part of their development.

\section{Class VI}

Class VI includes unpredictable factors that the majority viewed as being of low impact on TEPL but with strong opposition.

Economical Factors include (a) access to learning content will be controlled by corporate and institutional management; (b) TEPL suppliers don't see the SME market as an attractive market unless they can provide their services through an intermediary or they are supported by public funding; (c) TEPL products and services are mostly traded, regardless of the type or country origin of the supplier; (d) learning will increasingly become a business activity, following the business models, describing them as knowledge-intensive services.

Political Factors include (a) too many languages, cultural and legislative differences in Europe are hindering advancements in TEPL; (b) more centralized government and large corporations are making corporate training very centralized and directive; (c) public policies and funding instruments greatly stimulate demand for commercial TEPL products; (d) legislation and union agreements restrict the use of personal data of employees; (e) research and teaching approaches are constrained by government and corporate needs. Socio-cultural Factors include (a) a sudden leap towards self-directed learning styles will leave a mass of people without any possibilities of achieving skills; (b) the global village will make local habits disappear.

\section{CONCLUSION AND FUTURE WORK}

In this paper, we highlighted the integration of LM and $\mathrm{KM}$ and focused on learning as a skill and process aiming at enhancing the personal and professional performance and a means to improvement and effectiveness. We analyzed the learning process in terms of the SECI model and reported the results of a roadmap survey done in the framework of PROLEARN to identify the challenges and requirements for technology enhanced professional learning. In further work, we plan to continue the survey to take the analysis a step further and implement a complete, standard based learning platform called PALP (The 
Personalized Adaptive Learning Platform) including LOM-compliant automatic annotation of learning objects, learner model based information retrieval techniques as well as $\mathrm{KM}$ methods and tools. The main aim of PALP is to achieve the highly challenging task of personalized learning.

\section{REFERENCES}

Allee, V., (2000, August). eLearning is Not Knowledge Management. Learning in the New Economy eMagazine. Retrieved November 7, 2005, from http://www.linezine.com/2.1/features/vaenkm.htm

Barclay, R. O., Murray, P. C., 1997. What is knowledge management? Knowledge Praxis Magazine, Article. Retrieved November 2, 2005, from http://www.media-access.com/whatis.html

Bork, A., 2001. Tutorial Learning for the New Century. Journal of Science Education and Technology, vol 10, no.1, 57-71.

Chatti, M. A., Klamma R., Quix C. , Kensche, D., 2005. LM-DTM: An Environment for XML-Based, LIP/PAPI-Compliant Deployment, Transformation and Matching of Learner Models. Proceedings ICALT 2005, July 5-8, Kaohsiung, Taiwan, 567-569.

Drucker P. F., 1989. The New Realities: In Government and Politics, in Economics and Business, in Society and World View, Harper \& Row, New York.

Edmonds, G., Pusch, R., 2002. Creating shared knowledge: Instructional knowledge management systems. Educational Technology \& Society, vol. 5, no. 1 (Online serial).

Efimova, L., Swaak, J., 2003. Converging Knowledge Management, Training and e-Learning: Scenarios to Make it Work. Journal of Universal Computer Science, vol. 9, no. 3, 571-578.

Ellis, R. K., 2005. E-Learning Standards Update. Learning Circuits, Article. Retrieved October 26, 2005 , from http://www.learningcircuits.org/2005/jul2005/ellis.ht $\underline{m}$.

Grace, A., Butler, T., 2005. Learning Management Systems: A new beginning in the management of learning and knowledge. International Journal of Knowledge and Learning (IJKL), Vol. 1, Nos. 1-2.

Hackett, B., 2001. Beyond Knowledge Management: New ways to work and learn. The Conference Board, Research Report 1262-00-RR.

Hall, B., 2001. Learning management and knowledge management: Is the holy grail of integration close at hand? Brandon Hall Research, Whitepaper. Retrieved November 7, 2005, from http://www.brandonhall.com/public/whitepapers/lmk $\mathrm{m} /$

Hodgins, H. W., (2000, February). Into the Future. Learnativity, Vision Paper. Retrieved October 25, 2005, from http://www.learnativity.com/download/MP7.PDF.

Hodgins, H. W., (2005, February). Grand Challenges for Learning Objects. Presentation at Learntec, Karlsruhe, Germany.

Jarke, M., Klamma, R., 2002. Metadata and Cooperative Knowledge Management. Proc. 14th Intl. Conf. Advanced Information Systems Engineering, Toronto, Canada, LNCS 2348, pp. 4-20.
Learning Circuits Glossary, 2005. Retrieved November 7, 2005, from http://www.learningcircuits.org/glossary.

Lytras, M., Naeve, A., Pouloudi, A., 2005. Knowledge Management as a Reference Theory for E-Learning: A Conceptual and Technological Perspective. International Journal of Distance Education Technologies, Vol. 3, No. 2, pp. 1-12.

Moe, M., Blodgett, H., 2000. The knowledge web. Merrill Lynch.

Naeve, A., 2005. The Human Semantic Web - Shifting from Knowledge Push to Knowledge Pull, International Journal of Semantic Web and Information Systems (IJSWIS) Vol 1, No. 3, pp. 1-30.

Naeve, A., et al., 2005. A Conceptual Modelling Approach to Studying the Learning Process with a Special Focus on Knowledge Creation. Deliverable 5.3 of the Prolearn EU/FP6 Network of Excellence, IST 507310, June 2005.

Nonaka, I., 1994. A dynamic theory of organizational knowledge creation. Organization Science, Vol. 5, No. 1, pp. 14-37.

Nonaka, I., Konno, N., 1998. The concept of "Ba": Building foundation for Knowledge Creation. California Management Review, Vol. 40, No. 3.

Nonaka, I., Takeuchi, H., 1995. The Knowledge-Creating Company. Oxford University Press, Oxford.

Polanyi, M., 1967. The Tacit Dimension. New York, Anchor books (based on the 1962 Terry lectures).

Schank, R. C. 2002. Are We Going to Get Smarter? The Next Fifty Years. Science in the First Half of the Twenty-First Century. Edited by John Brockman. Trade paperback.

Spaniol, M., Klamma, R., Springer, L., Jarke, M., 2006. Aphasic Communities of Learning on the Web. International Journal of Distance Education Technologies (JDET), vol. 4, no. 1, 31-45.

Stacey, P., (2000, October). E-Learning \& Knowledge Management. E-Learning for the BC Tech Industry, Article. Retrieved November 2, 2005, from http://www.bctechnology.com/statics/pstaceyoct2700.html.

Stacey, P., (2003, February). People to People not just People to Content. E-Learning for the BC Tech Industry, Article. Retrieved November 2, 2005, from http://www.bctechnology.com/statics/pstaceyfeb1403.html.

Watkins, R., 2005. Preparing E-Learners for Online Success. Learning Circuits, Article. Retrieved October 26, 2005, from http://www.learningcircuits.org/2005/sep2005/watkin s.htm.

Wenger, E., 1998. Communities of practice: Learning, meaning and identity. Cambridge University Press. Cambridge, UK.

Wolpers, M., Grohmann, G., 2005. PROLEARN: technology-enhanced learning and knowledge distribution for the corporate world. Int. J. Knowledge and Learning, Vol. 1, Nos. 1/2, 44-61. 